\title{
The skeletal effects of congenital syphilis: the case of Parrot's bones
}

\author{
Garrard Cole $^{1, \star}$, Tony Waldron ${ }^{1}$, Susan Shelmerdine ${ }^{2}$, Ciaran Hutchinson ${ }^{3}$, Kieran McHugh ${ }^{2}$, \\ Alistair Calder ${ }^{2}$ and Owen Arthurs ${ }^{2,4}$ \\ ${ }^{1}$ UCL Institute of Archaeology, 31-34 Gordon Square, London WC1H 0PY, UK \\ ${ }^{2}$ Department of Clinical Radiology, Great Ormond Street Hospital, London WC1N 3JH, UK \\ ${ }^{3}$ Department of Histopathology, Great Ormond Street Hospital, London WC1N 3JH, UK \\ ${ }^{4}$ NIHR UCL GOS Institute of Child Health Biomedical Research Centre, London, UK \\ ${ }^{\star}$ Corresponding author. Email: tcrngco@ucl.ac.uk
}

\begin{abstract}
We provide a brief account of the life and work of Jules Parrot, a significant figure in French paediatrics, about whom almost nothing has been written. We focus on his work relating to congenital syphilis, specifically reporting on the examination of a collection of bones taken at autopsy from children with congenital syphilis. The collection of bones was brought to London in 1879 by Parrot to illustrate a talk that he gave before the Pathological Society of London. Subsequently, it travelled a circuitous route to the Royal Free Hospital pathology collection, where it remained until we (GC and TW) 'discovered' it. The bones represent the largest assemblage of material from cases of congenital syphilis in the UK and they are important as they clearly demonstrate the skeletal lesions associated with congenital syphilis and are now irreplaceable. The bones have been identified to anatomical element and have come from a minimum of eight children, both foetuses and neonates covering the period 30-50 weeks post-conception. Radiological and micro computerised tomography examinations were carried out and three-dimensional models printed at twice life size. The models are durable and can be handled with impunity by students and others wishing to familiarise themselves with the skeletal changes shown.
\end{abstract}

Keywords: Congenital syphilis; Jules Parrot; Micro CT; Diagnosis; 3D Printing

\section{Introduction}

In this paper, we give a brief account of the life and work of Jules Parrot, a significant figure in French paediatrics, about whom almost nothing has been written. His work on congenital syphilis, following on from earlier eighteenth and nineteenth century workers, made a major contribution to contemporary medical knowledge. He assembled a collection of bones taken at autopsy from children with congenital syphilis. They were brought to London in 1879 to illustrate a talk that he gave before the Pathological Society of London. The bones represent the largest assemblage of material from cases of congenital syphilis in the UK and they are important as they clearly demonstrate the skeletal lesions associated with congenital syphilis and are now irreplaceable. Modern computer imaging techniques allow for the production of durable three-dimensional (3D) models that can be handled with impunity by students and others wishing to familiarise themselves with the skeletal changes shown in patients affected by congenital syphilis.

\section{Congenital syphilis}

If a woman becomes pregnant in the early stages of syphilis infection, it is highly likely that her foetus will also become infected since the infectious organism, Treponema pallidum, is able to cross the 
placenta. The consequences for the foetus are potentially catastrophic. Half of those infected will die in utero or be stillborn, and of those that survive, half will likely die in the first few weeks of life. The children that do survive will suffer from a variety of sequelae, some evident in the first 2 years of life (the early signs), and some after the age of 2 (the late signs). It is now well understood that children in the early stages of congenital syphilis may suffer harm to the skeleton, ${ }^{1}$ but this was not always known and evidence to support this notion was often overlooked until the last quarter of the nineteenth century. Thus, although Nils Rosén ${ }^{2}$ had referred to the skeletal effects of congenital syphilis in his book on the diseases of children in 1764, little further investigation was carried out thereafter, thanks in large part to the magisterial comment by Paul Diday, and some of those who followed him, that, unlike in acquired syphilis, bony changes in congenital syphilis were 'très rare'. ${ }^{3}$ The most important contradictory publication that followed Rosén, although preceded by a number of individual case reports, ${ }^{4,5}$ was a paper by Georg Wegner, ${ }^{6}$ in which he described the lesions seen in the bones of 12 children who had died from congenital syphilis. Wegner found that all the elements of the skeleton might be involved with the typical findings comprising of wide spread periostitis, lesions in the ends of the long bones, ribs, clavicles and the bones of the skull, and separation of the epiphyses. A paper by Waldeyer and Köbner ${ }^{7}$ followed 2 years later, again based on 12 cases that confirmed Wegner's findings.

\section{Jules Parrot}

The next significant contribution to medical knowledge regarding syphilis came in $1872^{8}$ from Joseph-Marie-Jules Parrot (Figure 1). The son of a doctor, Parrot ${ }^{9}$ was born in 1829 in Exudeuil in the Dordogne. He began his education at l'Ecole Polytechnique in Paris, where he studied engineering before turning to medicine. He qualified from the Faculty of Medicine in Paris in 1852, gaining his MD 5 years later. Parrot was in the mould of the old physicians of the Paris School and it was important to him that he followed his patients from ward to mortuary as often as he could, performing their post-mortems himself. He was also something of a medical gadfly flitting from subject to subject, but in so doing, he made important contributions in several different fields. He had a passing interest in the localisation of language in the brain, demonstrating a case in $1863,{ }^{10}$ in which there was damage to the right side of the brain, but in which language had been preserved; this at a time when Broca was of the opinion that the language centres were located bilaterally in the brain.

\footnotetext{
${ }^{1}$ I. Simms et al., 'A Brief Recent History of the Epidemiology of Congenital Syphilis in the United Kingdom', International Journal of STD and AIDS, 29, 11 (2018), 1110-9.

${ }^{2}$ N. Rosén, Underrättelser Om Barn-Sjukdomar Och Deras Botemedel (Stockholm: Lars Salvius, 1764).

${ }^{3}$ Paul Diday, Traité de La Syphilis Des Nouveau-nés et Des Enfants à La Mamelle (Paris: Paul Masson, 1854).

${ }^{4} \mathrm{R}$. W. Taylor, Syphilitic Lesions of the Osseous System in Infants and Young Children (New York: William Wood \& Co., 1875).

${ }^{5}$ Stafford McLean, 'I. The Roentgenographic and Pathologic Aspects of Congenital Osseous Syphilis', American Journal of Diseases of Children, 41, 1 (1931), 130-52.

${ }^{6}$ G. Wegner, 'Ueber Hereditäre Knochensyphilis Bei Jungen Kindern', Archiv Für Pathologische Anatomie Und Physiologie, 50 (1870), 305-22.

${ }^{7}$ W. Waldeyer and H. Köbner, 'Beiträge Zur Kenntniss Der Hereditäre Knochensyphhilis', Archiv Für Pathologische Anatomie Und Physiologie, 55 (1872), 367-79.

${ }^{8}$ J. Parrot, 'Sur Une Pseudo-Paralysie Causée Par Une Altération Du Système Osseux Chez Les Nouveau-nés Atteints de Syphilis Héréditaire', in Charles-Edouard Brown-Séquard et al. (eds), Archives de Physiologie Normale et Pathologique. Tome Quatrième, Vol. 4 (Paris: Victor Masson et Fils, 1871), 319-33, 470-90, 612-23.

${ }^{9}$ There is very little documentary evidence relating to Parrot himself. With assistance, we have conducted searches of the medical archives of Paris hospital archive system. Very little was uncovered; a letter from Dr Parrot (9L85) that relates to the creation of a service dedicated to treat acute and chronic diseases in the Hospital for Sick Children ('Enfants Malades') around 1874; a copy of the paper by Thieffry mentioned explicitly later in this text; and a collection of 88 wax masks donated to the Mussée du Moulage, where it is known as the Parrot Collection.

${ }^{10}$ J. Parrot. 'Atrophie Complète du Lobule de l'Insula et de la Troisième Circonvolution du Lobe Frontal Avec Conservation de l'Intelligence et de la Faculté du Langage Articulé', Bulletins de la Société Anatomique, 38 (1863), 372-401.
} 


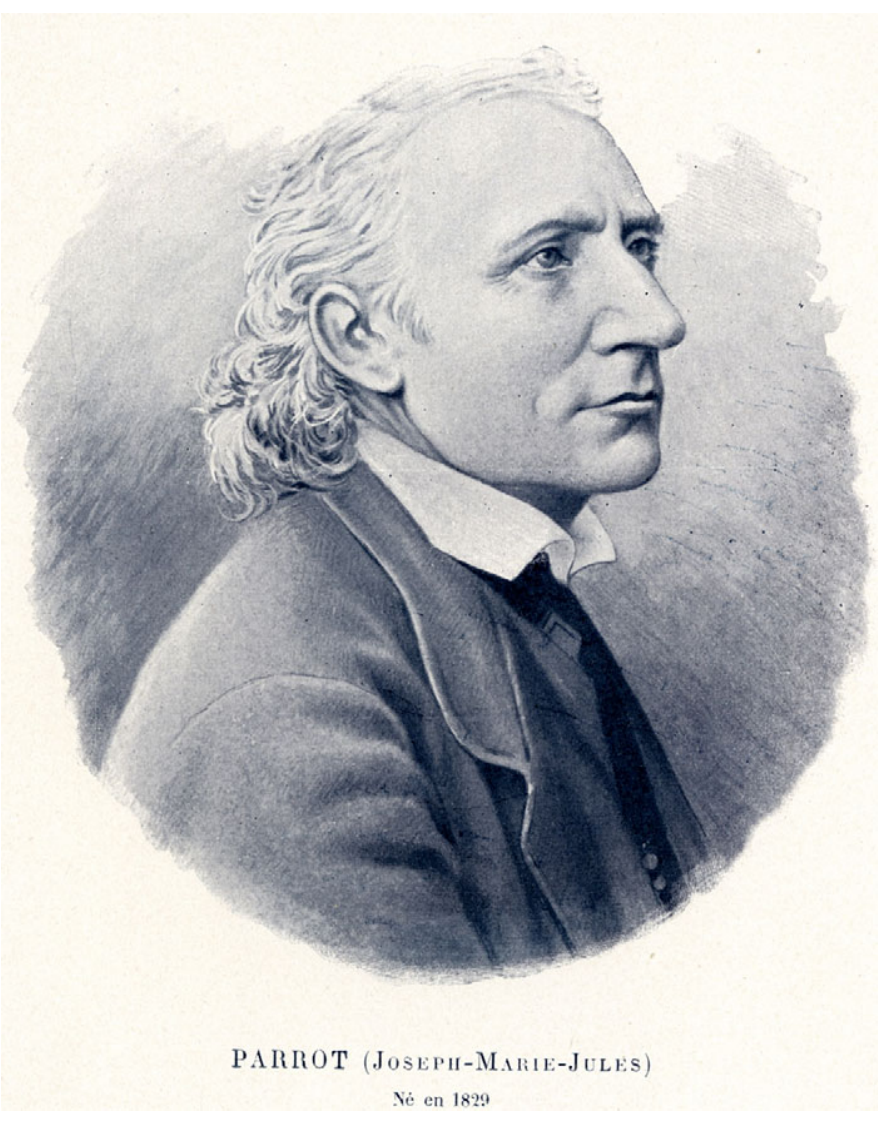

Figure 1. (Colour online) Joseph Marie Jules Parrot (image from Corlieu (A.), Centenaire de la Faculté de Médecine de Paris (17941894), Paris: F. Alcan, 1894, held in the collections of the bibliothèque inter-universitaire de santé, distributed freely by Wikimedia).

Parrot's most significant early studies, however, were on heart sounds and vascular bruits, particularly those heard in the neck, but he also made important contributions to the natural history of tuberculosis and in $1876^{11}$ presented his findings from post-mortems on 145 children, in which he noted that infection of the bronchial glands was always accompanied by a pulmonary lesion, even if the latter was merely the size of a pin-head; this later came to be known as Parrot's Law. In the same year, he also gave the first account of what was later referred to as the Ghon focus - the tubercular lesion in the apex of the lung. A couple of years later, he described a patient with short-limbed dwarfism and coined the term achondroplasia for it. Some years later, in $1881^{12}$, he gave the first description of the Pneumococcus as the cause of bronchopneumonia, in a paper co-authored with Louis Pasteur, with whom he collaborated on a number of occasions.

In 1867, Parrot joined l'Hospice des Enfants Assistés in Paris, where he worked for the remainder of his professional life. He was elected as a member of l'Académie de Médecine in 1878 having been appointed to the Chair of the History of Medicine 2 years previously in 1876. In 1879, however, after some insistence, he managed to convert the chair to one of paediatrics based at his hospital. In addition to

\footnotetext{
${ }^{11}$ J. Parrot. 'Recherches Sur Les Relations qui Existent Entre Les Lésions des Poumons et Celles des Ganglions TrachéoBronchiques', Comptes Rendus de la Société de Biologie, 6 (1876), 308-9.

${ }^{12} \mathrm{~J}$. Parrot 'L'organisme Microscopique Trouvé par M. Pasteur dans la Maladie Nouvelle Provoquée par la Salive d'un Enfant Mort de la Rage', Bulletin de l'Académie de Médecine, 10 (1881) 379.
} 
his medical interests, he was also a keen anthropologist and was a co-founder of the Société Français d'Anthropologie and served as its president in 1881 .

When Parrot took up the study of paediatrics, it was estimated that $10 \%$ of the population of Paris ${ }^{13}$ had syphilis, and babies born to syphilitic mothers would have been commonly seen. At the children's hospital, Parrot had ample material to study. The hospital had a population of about 3000 children with a childhood mortality rate of 33\%; among the youngest children, the mortality rate was $60 \%$, and $350-450$ autopsies were carried out each year. ${ }^{14}$ Many of the deaths would have been due to congenital syphilis and Parrot became particularly interested in its effects on the skeleton. His 1871 paper $^{15}$ is notable for his description of his so-called pseudo-paralysis. Parrot saw that children with congenital syphilis tended to lie still to avoid moving their swollen joints, especially those of the upper limb, since movement might cause them pain. A much more extensive work, which included several beautiful colour illustrations of the bony lesions of congenital syphilis, followed in $1886,{ }^{16} 3$ years after his death at the early age of 53 after a long illness.

Parrot's 1871 paper described the pathological changes in 12 children - this seemed to be a number favoured by most investigators - who had died from congenital syphilis and in it, he categorised his findings into four main groups as follows:

- The presence of periosteal new bone (which he referred to as osteophyte);

- Changes in the metaphyses of the limb bones, linking these with the pseudo-paralysis;

- What he referred to as medullation, an increase in the volume of the long bones; and

- Spongy changes at the metaphyses, especially of the humerus, as the disease approached what he called the 'rachitic' stage.

He later noted ${ }^{17}$ that the long bones could fracture in utero during the 'rachitic' stage of the disease, often with subsequent healing.

At the time Parrot was writing, the bony lesions of congenital syphilis were frequently confused with those of rickets, and there was a widespread belief - which Parrot also shared - that rickets was caused by congenital syphilis. There was further confusion between the lesions of rickets and scurvy, and hence those of congenital syphilis, that was not finally disentangled until Thomas Barlow did so in $1888 .{ }^{18}$

In 1879, Parrot was invited to address the Pathological Society of London on the subject of the skeletal effects of congenital syphilis. The session was chaired by Jonathan Hutchinson, the President of the Society, who was well known as the greatest authority on syphilis in England; Barlow introduced Parrot to the audience and followed Parrot's paper with one of his own (with David Lees, a colleague at Great Ormond Street Hospital), in which he described changes in the skull in congenital syphilis, illustrating his lecture with three live patients. ${ }^{19}$

It is not clear who invited Parrot to attend and speak at this London talk and an extensive search of archives in both Paris and London have yielded no clues. However, given that Barlow introduced his paper to the Society and that Parrot donated his collection to Great Ormond Street Hospital it seems that

\footnotetext{
${ }^{13}$ J. Harsin, 'Syphilis, Wives, and Physicians: Medical Ethics and the Family in Late Nineteenth-Century France', French Historical Studies, 16 (1989), 72-95.

${ }^{14}$ S. Thieffry, 'La Découverte de La Syphilis Congénitale Par Jules Parrot à l'Hospice Des Enfants Assistés Il y Un Siècle', Bulletin de L'Académie Nationale de Médicine, 8 (1980), 725-9.

${ }^{15}$ J. Parrot, 'Sur Une Pseudo-Paralysie Cause Par Un Altération Du Système Osseux Les Nouveau Nés Atteints de Syphilis Héréditaire', Archives de Physiologie Normal et Pathologique, 4 (1871), 319-33.

${ }^{16}$ J. Parrot, Le Syphilis Héréditaire et Le Rachitis (Paris: Paul Masson, 1886).

${ }^{17}$ J. Parrot, 'Les Lésions Osseuses de La Syphilis Héréditaire et Le Rachitis', Archives et Physiologie Normale et Pathologique, 30 (1876), 133-9.

${ }^{18}$ Thomas Barlow, 'On Cases Described as “Acute Rickets” Which Are Probably a Combination of Scurvy and Rickets: The Scurvy Being an Essential and the Rickets a Variable Element', Archives of Disease in Childhood, 66 (1883), $223-52$.

${ }^{19}$ Thomas Barlow and D. B. Lees, 'On Lesions of the Cranial Bones in Congenital Syphilis (Illustrated by Three Living Cases)', Transactions of the Pathological Society of London, 30 (1879), 350-3.
} 

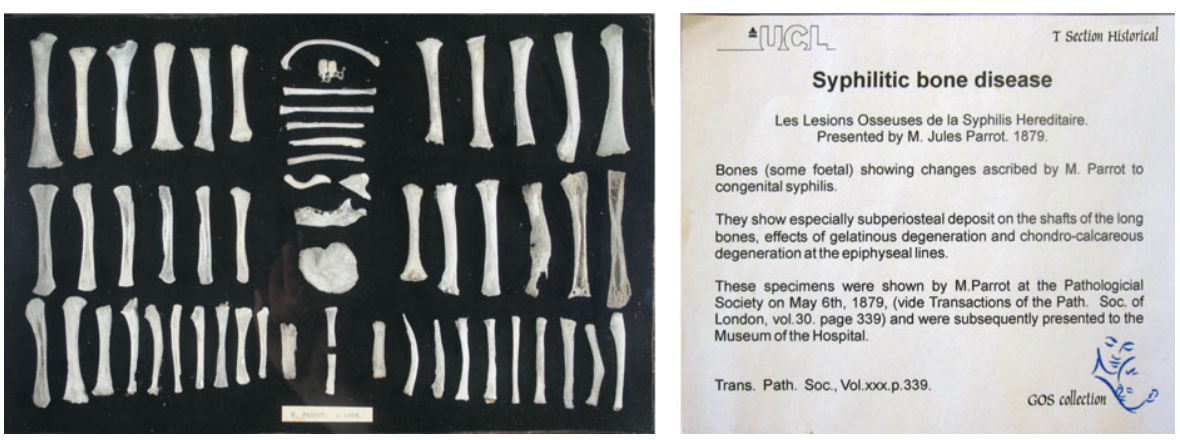

Figure 2. (Colour online) The Parrot collection of bones laid out in a display case with associated limited documentation (case photograph provided courtesy of Emilia Kingham, UCL Culture, printed with permission of UCL Culture).

Barlow was responsible. In the lecture, Parrot simplified the skeletal changes he noted into two types atrophic and osteophytic. The atrophic type took two forms, the first, which was the most common, and found in the skull and the long bones, he called gelatiniform. This was marked by a change in the colour of the bones, and the appearance of a gelatinous tissue that replaced part of the bone. The second phase, Parrot called the chondro-calcareous type, in which the growth plate was thickened and more friable than usual, leading to separation of the epiphysis. This marked the onset of the 'rachitic' phase, caused by the syphilis, which was associated with the pseudo-paralysis that he had described previously. The osteophytic changes were much the more frequent, and were characterised by the widespread development of new bone affecting first the humerus and the tibia, and then the femur and the ulna; and, with extensive change, any or all the skeleton might be affected. The new bone was on both the external and the internal surfaces, although the bones had to be cut longitudinally for the endosteal new bone to be seen.

Parrot's lecture was published in both the Society's Transactions ${ }^{20}$ and, in an English translation, in the Lancet. ${ }^{21}$ At the end of the lecture, Parrot exhibited some bones that he had brought with him from his own collection, perhaps some from the cases he had described in his 1871 paper. When he went back to Paris, Parrot left the specimens with Barlow again suggesting that it was Barlow who had invited Parrot to speak, the specimens being by way of a thank you. The bones were subsequently incorporated into the pathology museum at the Great Ormond Street Hospital, where Barlow was on the staff. During a much later reorganisation, however, the bones were taken from the museum and finally came to rest in a cupboard in the Royal Free Hospital, where they were subsequently discovered by the authors. It seems likely that Parrot also brought some syphilitic skulls with him to the lecture, ${ }^{22}$ but whether he also left those behind on his return to Paris is not clear; there is certainly no trace of them at either Great Ormond Street or the Royal Free Hospitals and they must be presumed to be lost.

\section{Material}

The bone collection presented at the lecture was afterwards donated by Parrot to Dr Thomas Barlow, then working at the Great Ormond Street Hospital (GOSH) for children. The collection remained at GOSH probably until the 1960s when it was transferred to the Royal Free Hospital where it remained until we (GC and TW) 'discovered' it in a cupboard in which it had been placed at some time. The bones from the lecture were mounted at a later date in a case (Figure 2) - a historical artefact in its own right, held in the care of UCL Culture, and handled only by a conservator. Within the case, the bones had been

\footnotetext{
${ }^{20}$ J. Parrot, 'Les Lésions de Syphilis Héréditaire', Transactions of the Pathological Society of London, 30 (1879), 339-50.

${ }^{21}$ M. J. Parrot, 'The Osseous Lesions of Hereditary Syphilis', The Lancet, 113, 2907 (1879), 696-8.

${ }^{22}$ D. B. Lees, 'The Cranial Bones in Congenital Syphilis', British Medical Journal, 2 (1879), 799.
} 
mounted on a wooden backing plate held in place by hand-made screws, indicating that it originated before the early part of the twentieth century. A total of 56 extremely fragile bones were present, representing anonymous clinical material from Parrot's cases at l'Hospice des Enfants Assistés in Paris.

\section{Methods}

The primary methods of assessment were visual inspection of X-ray data, computerised tomography (CT) data and of accurate replicas produced by $3 \mathrm{D}$ printing. The CT scans provided source data for subsequent processing for the $3 \mathrm{D}$ printing process.

The display case and bones within could only be handled by a conservator. The bones were carefully removed from the velvet-covered backing plate on which they were fastened, with the exception of one particularly fragile specimen that could not be unglued, so the backing velvet was cut away leaving some of it attached to the bone. The bones were then transferred to individual custom-made low-density foam blocks and encased in a conservation grade cardboard box and radiographed. In order to investigate the material further, it was decided to use micro-focus CT (micro-CT) as conventional medical CT systems would not have had sufficient resolution to display the fine detail of the pathological bony changes. ${ }^{23}$

The samples were mounted two at a time on the turntable of a Nikon Metrix XT225 micro-CT machine, one box above another with the long axis oriented horizontally. The micro-CT was operated at about $90 \mathrm{kV}$ $150 \mu \mathrm{A}$ with a $1 \mathrm{~mm}$ aluminium filter. The magnification was adjusted to give maximum image size, governed by the dimensions of the larger element. The voxel size varied depending on specimen size, from $30 \mu \mathrm{m}$ to $45 \mu \mathrm{m}$ as appropriate. The data were reconstructed using the scanner's proprietary software package.

It was clear from the results that most elements had been half-sectioned, usually in a longitudinal plane. This had presumably been done by Parrot himself, as we know that he frequently sectioned his specimens with a scalpel so that he could examine the internal structure.

In order to make a diagnosis of disease, it is important to know which anatomical elements demonstrated the pathological lesions. The presence of half-sectioned material raised the possibility, however, that some specimens could be paired to form whole elements. Radiographs and micro-CT images were reviewed by three consultant paediatric radiologists with interests in bone disease and post mortemimaging ( $\mathrm{AC}, \mathrm{OA}$ and $\mathrm{KMcH}$ ), working in consensus. It was possible to anatomically classify about half of the bones from the imaging data. For these reasons, it was decided to create 3D printed models to allow for better handling and visualisation of the specimens. X-ray images of the 3D printed models were taken to provide a means of assessing the quality of reproduction.

\section{Results}

Once the models had been printed, it was possible to anatomically classify all but two of the bones (see Table 1). It was also possible to age the material using standard age-length charts; from these, it was found that the bones ranged in age from 30 to 50 weeks post-conception (Table 2), so that the specimens had come from a mixture of premature and term neonates, as well as very young infants. It was also possible to pair eight of the elements to form four complete bones, two humeri, one tibia and one fibula, all from one or more individuals aged 42 weeks post conception. The collection represents a minimum number of eight individuals (Table 3) based on counts of right-side long bone elements in each 4 week postconception age band. The X-ray data for the 3D models showed a close match to the original X-ray images of the actual specimens.

\footnotetext{
${ }^{23}$ Susan C Shelmerdine et al., '3D Printing from Microfocus Computed Tomography (Micro-CT) in Human Specimens: Education and Future Implications', The British Journal of Radiology 91 (2018), 20180306. https://doi.org/10.1259/ bjr.20180306.
} 
Table 1. Total number of bones for each skeletal element represented in the Parrot bone collection

\begin{tabular}{lc}
\hline Anatomical element & Number present \\
\hline Tibia & 18 \\
\hline Humerus & 9 \\
\hline Femur & 7 \\
\hline Ulna & 6 \\
\hline Fibula & 4 \\
\hline Radius & 3 \\
\hline Rib & 2 \\
\hline Clavicle & 1 \\
\hline Ilium & 1 \\
\hline Mandible & 1 \\
\hline Sacrum & 1 \\
\hline Scapula & 1 \\
\hline Unknown & 2 \\
\hline
\end{tabular}

Table 2. Post-conception age estimates taken from individual foetal and neonate long bones in the Parrot collection

\begin{tabular}{lr}
\hline Age (weeks) & Number \\
\hline $30-$ & 4 \\
\hline $34-$ & 3 \\
\hline $38-$ & 24 \\
\hline $42-$ & 11 \\
\hline $46-$ & 2 \\
\hline $50+$ & 1 \\
\hline
\end{tabular}

Table 3. Minimum number of individuals (MNI) represented in each 4 week post-conception age band

\begin{tabular}{lc}
\hline Age (weeks) & MNI \\
\hline $30-$ & 1 \\
\hline $34-$ & 1 \\
\hline $38-$ & 3 \\
\hline $42-$ & 1 \\
\hline $46-$ & 1 \\
\hline $50+$ & 1 \\
\hline
\end{tabular}

The MNI value is derived from counts of right-side long bone elements. 


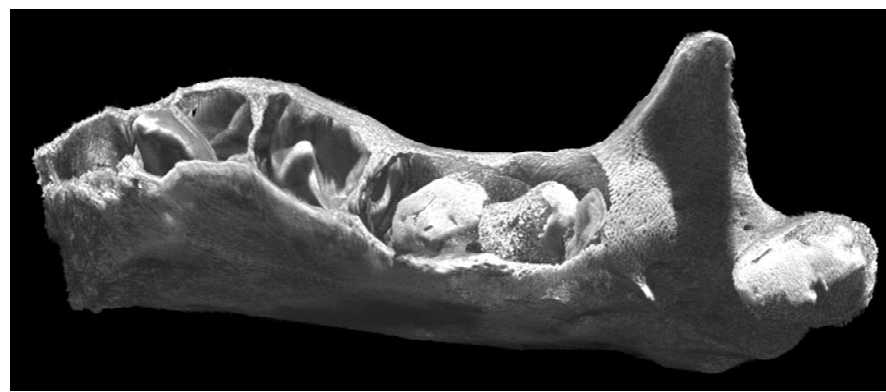

Figure 3. Three-dimensional (3D) reconstruction of the right side of the mandible. There are two large non-dental objects in the sockets for the deciduous molars. These were identified as parts from the sacrum, part of which was included in the collection (author photograph).

\section{Discussion}

The sectioning was carried out rather inexpertly and in two instances the bones were sectioned differently at the proximal and distal ends which made assessment difficult without 3D reconstruction. In Parrot's defence, however, the difficulty in manipulating such small, delicate specimens should not be overlooked.

The pathological features of the bones were faithfully reproduced in the models. They all showed the presence of extensive new bone on both the periosteal and endosteal surfaces. Twenty-two long bones had been separated from their growth plates; one tibia showed medial metaphyseal destruction of the proximal tibia, known as Wimberger's corner $\operatorname{sign}^{24}$ (not Wimberger's ring sign of the epiphysis, a sign of scurvy). The solitary clavicle present was much curved and the acromial end was greatly expanded by the presence of new bone, an appearance which was the converse of Higouménakis' sign ${ }^{25}$ in which the sternal end is affected; this does not seem to have been described before. Five of the long bones had been fractured in utero and were in the process of healing. One specimen had a well-healed mid-shaft fracture. Another had a markedly misaligned mid-shaft fracture with extensive callus and a third showed evidence of failure to fuse possibly the result of limb movement in utero. Thirteen of the bones showed signs that McLean $^{26}$ considered were pathognomonic of congenital syphilis including a number with submetaphyseal rarefication, and one with a saw-tooth metaphysis.

A single mandible was present with anomalous structures glued into the sockets of right second deciduous molar and the first permanent molar (see Figure 3). After much deliberation, it was decided that these structures were sacral segments. This was confirmed when they were printed individually as the models fitted exactly into the loops of dried tissue around the main sacral element. How (or why) they came to be where they were remains a mystery.

The cusps of the lateral deciduous incisor and first deciduous molar in the extant right semi-mandible were reminiscent of the changes seen in the so-called mulberry molars found in congenital syphilis. ${ }^{27}$ There were fine, deep incised grooves on the anterior lateral incisor with what appeared to be channels

\footnotetext{
${ }^{24}$ Hans Wimberger, 'Klinisch-Radiologische Diagnostik von Rachitis, Skorbut Und Lues Congenita Im Kindesalter', in F. Klaus et al. (eds), Ergebnisse Der Inneren Medizin Und Kinderheilkunde (Berlin, Heidelberg: Springer, 1925), 264-370. This classic paper also clarifies the age distribution of the three conditions, which is an important aid in distinguishing them when only the bones remain.

${ }^{25}$ G. K. Higouménakis, 'Neues Stigma der kongenitalen Lues. Die Vergrößerung des sternalen Endes des rechten Schlüsselbeins, seine Beschreibung, Deutung und Ätiologie', Deutsche Zeitschrift für Nervenheilkunde, 114, 4 (1930), $288-99$.

${ }^{26}$ Stafford McLean, 'V. Osseous Lesions of Congenital Syphilis: Summary and Conclusions in One Hundred and Two Cases', American Journal of Diseases of Children, 41, 6 (1931), 1411-8.

${ }^{27}$ Simon Hillson et al., 'Dental Defects of Congenital Syphilis', American Journal of Physical Anthropology, 107, 1 (1998), $25-40$.
} 


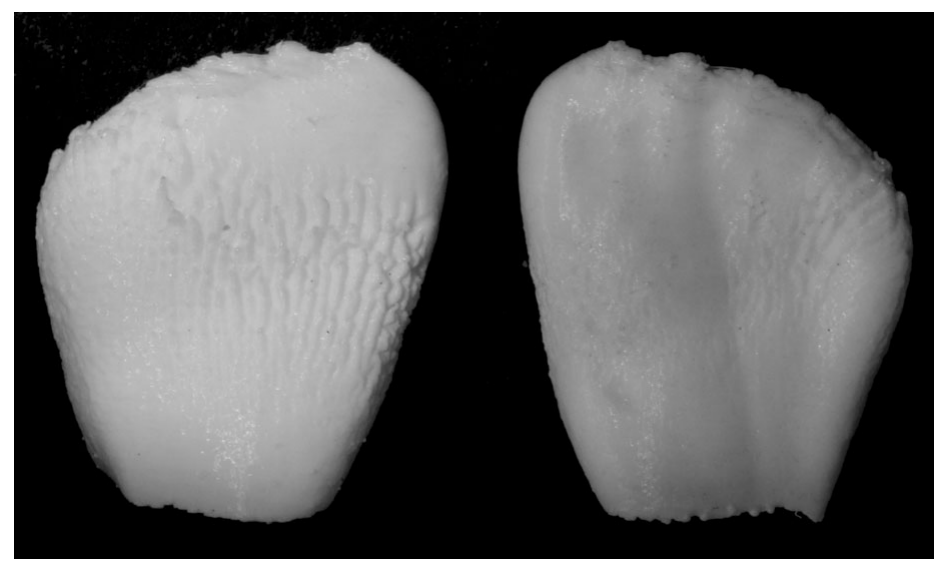

Figure 4. Buccal and lingual views of the crown of the right lateral deciduous incisor, showing the irregular horizontal and vertical fissures referred to above. There are also two round hypoplastic defects; one near the distal mamelon on the buccal surface and the other on the inferior medial aspect of the lingual surface (author photograph).

within the enamel itself; the exact significance of these changes is unclear (see Figure 4). This appears to be a new observation regarding the deciduous dentition. Similar changes in the permanent dentition of a child aged $8-10$ years have been reported by Ioannou et al. ${ }^{28}$ in a paper describing the use of Hutchinson', ${ }^{29}$ method for differentiating the effects of mercury on syphilitic teeth. They suggest this particular case may provide evidence for the use of mercury as a treatment for congenital syphilis. Hutchinson describes changes to the permanent dentition of children affected by congenital syphilis that he notes are commonly associated with mercurial treatment. He does acknowledge the changes may also occur in absence of such treatment. The changes we observe in the early stages of the deciduous dentition (about 26 weeks post-conception) preclude direct mercurial treatment of the individual.

Whilst we have no doubt about Parrot's ability to correctly diagnose congenital syphilis, the poorly documented provenance of the material under discussion raises questions about their authenticity. Consequently, we consider other documentary evidence ${ }^{15,24,26}$ to infer the collection is indeed authentic, showing classic signs of the disease.

Clinical work by Wimberger ${ }^{24}$ provided useful evidence for the differences between congenital syphilis, rickets and scurvy. The three diseases show distinctly different patterns of age of incidence (Table 4). The skeletal lesions of congenital syphilis have a distinct pattern of early incidence (earlier than 3 months post-natal) reflecting early mortality and incidence of in late childhood. All of the specimens from the Parrot collection fall in to this early incidence group and none of the bones showed evidence of rickets as we thought might have been the case given the failure of Parrot's contemporaries to distinguish clearly between the skeletal changes in this condition and congenital syphilis.

The internal structure of the specimens exactly reflected the radiological appearances, one femur, eg., showing longitudinal, thickened bars of bone which were the substrate of the 'celery stalk' sign seen on X-ray. Other bones had an appearance similar to that illustrated in Parrot's publications ${ }^{16}$ (see Figure 5).

\footnotetext{
${ }^{28}$ Stella Ioannou et al. 'Diagnosing Congenital Syphilis Using Hutchinson's Method: Differentiating between Syphilitic, Mercurial, and Syphilitic-Mercurial Dental Defects', American Journal of Physical Anthropology, 159, (2015), 617-629.

${ }^{29}$ Jonathan Hutchinson, Illustrations of Clinical Surgery Consisting of Plates, Photographs, Woodcuts, Drawings, etc. (London: J \& A Churchill, 1875), 53-57.
} 
Table 4. Earliest age of incidence for skeletal lesions in congenital syphilis, rickets and scurvy based on evidence collected by Wimberger.

\begin{tabular}{l}
\hline Disease \\
\hline Congenital syphilis \\
\hline Scurvy
\end{tabular}
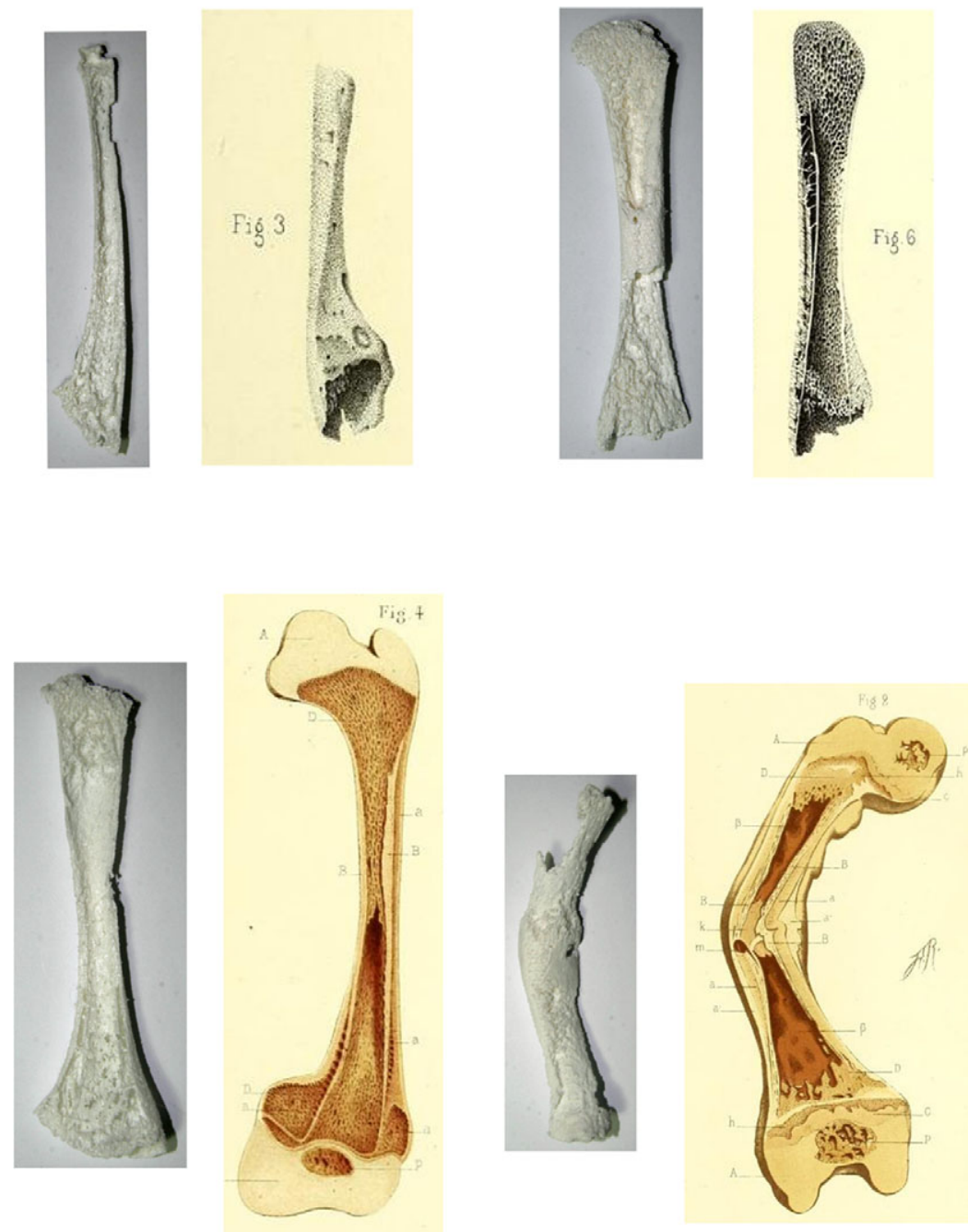

Figure 5. (Colour online) Comparison of 3D prints of selected elements from the collection with illustrations of specimens included in Parrot's papers (3D prints are author photographs, other images are from Parrot 1886). The illustrations show similarities in metaphyseal changes and angulation of healed mid-shaft fracture. 


\section{Conclusions}

The value of collections such as the one described here is threefold:

First, they provide an opportunity to confirm diagnoses made in the past using modern methods of investigation such as CT scans or DNA analysis where appropriate. This may later help better to clarify the historiography of certain diseases.

Second, having confirmed the diagnosis, they provide an opportunity to learn more about the pathology of the disease (or diseases) in question. In the case of congenital syphilis, this is especially important given that in the present-day congenital syphilis can be easily prevented by treatment to the mother, ${ }^{30}$ and skeletal manifestations are hardly ever likely to be seen. And even if this were not the case, the collection and storage of foetal or infant material is now virtually unobtainable. ${ }^{31}$ The collection therefore forms an important, possibly unique, reference collection.

Third, the bones can form an important reference source against which those from other historic or archaeological contexts can be compared. Printed 3D models, if they can be made, as here, can faithfully reproduce the lesions and provide excellent teaching material that can be handled and inspected without fear of damage, leaving the originals intact and securely conserved.

Acknowledgements. The authors would like to thank Subhadra Das, UCL Culture, for granting permission to investigate the Parrot Collection and Emilia Kingham, UCL Culture, for preparing the specimens for scanning. They would also like to thank Agathe Ribéreau-Gayon, UCL Institute of Archaeology, Sylvie Dorison, Musée du Moulages, Hôpitaux de Paris and Hélène Servant, Département des Patrimoines Culturels, Hôpitaux de Paris for their invaluable assistance in searching the medical archives of the Paris hospital system for material about Jules Parrot. We would also like to thank the two anonymous reviewers for their helpful contributions.

\footnotetext{
${ }^{30}$ Marco De Santis et al., 'Syphilis Infection during Pregnancy: Fetal Risks and Clinical Management', Infectious Diseases in Obstetrics and Gynecology, 2012 (2012), 430585.

${ }^{31}$ Angus Turnbull et al., 'Hospital Autopsy: Endangered or Extinct?', Journal of Clinical Pathology, 68 (2015), 601-4.
}

Cite this article: Cole, G., Waldron, T., Shelmerdine, S., Hutchinson, C., McHugh, K., Calder, A. and Arthurs, O. 2020. The skeletal effects of congenital syphilis: the case of Parrot's bones. Medical History 64: 467-477, https://doi.org/10.1017/ mdh.2020.41 